\title{
38-Osmanlı'nın Son Şair Okulu Talebelerinden Biri: Hüseyin Hüsnî Efendi ve Mecmûa-i Edebiyye'si
}

\section{Özlem BATĞI AKMAN ${ }^{1}$}

APA: Batğı Akman, Ö. (2022). Osmanlı’nın son şair okulu talebelerinden biri: Hüseyin Hüsnî Efendi ve Mecmûa-i Edebiyye'si. RumeliDE Dil ve Edebiyat Araştırmaları Dergisi, (26), 650-657. DOI: 10.29000/rumelide.1074006.

\section{$\ddot{O} \mathbf{z}$}

Klasik Türk şiiri XVIII. yüzyıldaki değişim ve dalgalanmaların da etkisiyle XIX. yüzyılda farklı bir düzlemde ilerlemeye devam etmiş ve bu anlayışla eser veren sanatkarlarını peyderpey yitirmeye başlamıştır. Varlık hayatı son bulsa da etkisi devam eden bu şiir anlayışının XIX. yüzyıldaki en büyük karşıtları "yeni" bir sanat anlayışı getirme gayesindeki sanatkârlar olmuştur. Yeniye direnen, gelenekten kopma niyetinde olmayan şairler ise bir arada olma ve sanat üretme gayesi ile tıpkı klasik dönem şairlerinin edebi meclisleri gibi topluluklar kurup "eski” diye adlandırılan tarzda şiirler yazmaya devam etmişlerdir. Muallim Nâcînnin Tercüman-ı Hakikat gazetesinden ayrıldıktan sonra Saâdet gazetesinde kurduğu Ukâz-ı Osmânî, Osmanlının son şair okulu olarak bilinmektedir. Geleneğe bağlı şairlerin bir araya geldikleri bu okulun bir mensubu da çalışmamıza konu olan Hüseyin Hüsnî'dir. Hüseyin Hüsnî Efendi hakkında kaynaklarda sınırlı bilgiler bulunmaktadır. Şairin Mecmûa-i Edebiyye isimli eseri 1892 yılında İstanbul'da Mahmud Bey matbaasında basılmıştır. Eserde gazel, tahmis, müseddes, kıta ve rubâî gibi farklı nazım şekillerinden şiirler yer almaktadır. Klasik şiirin benzetme unsurlarına ve hayal dünyasına hâkim olduğu anlaşlan şair, aruzu da nispeten başarılı bir şekilde kullanmıştır. Bu çalışmada Hüseyin Hüsnî Efendi'nin Osmanlı'nın son şair okuluna mensubiyeti, şiir üslubu ve daha önce üzerine herhangi bir çalışma yapılmamış eseri Mecmûa-i Edebiyye hakkında bir değerlendirme yapılacak, eser ilim alemine tanıtılacaktır.

Anahtar kelimeler: Hüseyin Hüsnî, Ukâz-ı Osmânî, Muallim Nâci, Osmanlı Şair Okulu, Mecmua

\section{One of the last poet school students of the Ottoman Empire: Hüseyin Hüsni and His Mecmau-i Edebiyye}

\begin{abstract}
Classical Turkish poetry continued to progress on a different plane in the 19th century with the influence of the changes and fluctuations in the XVIII century and gradually began to lose its artists who worked with this understanding. The greatest opponents of this understanding of poetry whose influence continued even though its existence came to an end, in the 19th century were the artists who aimed to bring a new understanding of art. Poets who resist the new and do not intend to break with tradition for the purpose of being together and producing art, just like the literary assemblies of classical poets, they established communities and continued to write works in the style of poetry which is called old.Ukaz-1 Osmani, founded by Muallim Nâci in the newspaper Saadet after leaving Tercüman-ı Hakikat newspaper, is known as the Last Poet School of the Ottoman Empire. Hüseyin Hüsnî, who is the subject of our study, is a member of this school where the poets of tradition come together.There is limited information about Hüseyin Hüsni Efendi in the sources. The poet's work

Dr. Öğr. Üyesi, Siirt Üniversitesi, Türk Dili ve Edebiyatı Bölümü, Eski Türk Edebiyatı ABD (Siirt, Türkiye), ozlem.batgi@siirt.edu.tr, ORCID ID: 0000-0002-0042-4714 [Araştırma makalesi, Makale kayıt tarihi: 11.01.2022-kabul tarihi: 20.02.2022; DOI: 10.29000/rumelide.1074006]

Adres

RumeliDE Dil ve Edebiyat Araştırmaları Dergisi Osmanağa Mahallesi, Mürver Çiçeği Sokak, No:14/8 Kadıköy - İSTANBUL / TÜRKIYE 34714 e-posta: editor@rumelide.com tel: $+905057958124,+902167730616$

Address

RumeliDE Journal of Language and Literature Studies

Osmanağa Mahallesi, Mürver Çiçeği Sokak, No:14/8

Kadıköy - ISTANBUL / TURKEY 34714

e-mail: editor@rumelide.com,

phone: +90 $5057958124,+902167730616$
\end{abstract}


named Mecmua-i Edebiyye was published in Istanbul in 1892 at the Mahmud Bey printing house. There are poems in different verse forms such as gazel, tahmis, müseddes, kita and rubai in the work. The poet, who has mastered the simile elements and imagination of classical poetry, has successfully used the prosody.In this study, an evaluation will be made about Hüseyin Hüsnî Efendi's membership to the Ottoman's Last Poet School, poetic style and his work Mecmua-i Edebiyye, which has not been studied before.

Keywords: Hüseyin Hüsni, Ukaz-1 Osmani, Muallim Naci, The Ottoman Poet School, Magazine

\section{Giriş}

Osmanlı coğrafyasında yazılmış biyografi eserlerinde, klasik Türk şiiri geleneğine mensup üç binden fazla şairden söz edilmektedir. Her yüzyılın bir öncekinden daha çok şair yetiştirdiği ve yetişen her bir şairin bir diğerinin yetişmesine katkı sağladığı bu gelenek klasikleşmiş ve poetikasını oluşturmuş bir şiir geleneğidir. Mazmunları, hayal dünyası ve ahenk unsurları ile sürekli gelişen gelenekte "usta-çırak ilişkisi diyebileceğimiz nazire okulu” (Kurnaz, 2007: V), şairlerin bir araya gelip şiir meşki yaptıkları edebi mahfiller şair yetiştirmede önemli rol oynamıştır. Osmanlı şair okulları kimi zaman şiir meşkine dayanan uygulamalarla kimi zaman da edebi toplantılarla farklı şekillerde devam etmiştir. XIX. yüzyıla gelindiğinde şair meclislerinin sayısının arttığı, bu meclislerin yeni bir kimlik kazandığı ve bu tarz toplulukların zamanla akademik bir yapıya dönüştüğü görülür (Özgül, 2012: 14). XX. yüzyıla gelindiğinde de benzer örnekler karşımıza çıkar, köşk, konak ve evler birer meclis ortamı olarak okul görevini yerine getirir (İbnülemin Kemal İnal'ın konağı gibi²).

XIX. yüzyılın ikinci yarısında ilk şiirleri Tercümân-ı Hakîkat'te çıkan Muallim Nâcî sonraları aynı gazetenin edebiyat sayfasını yönetmeye ve artan ilgi sonucu gazeteye gelen gençlerin şiirlerinin kritiğini yaparak bir anlamda onlara muallimlik yapmaya başlamıştır (Çağın, e-makale). O dönemde Tercümânı Hakîkat'in edebiyat sayfası adeta bir klasik şiir meclisine dönmüş, Nâcî’nin şiirlerine yazılan nazirelerin çokluğu onun mevcut ve yeni yetişen şairler üzerindeki etkisini ispatlar hale gelmiştir.

Hakîkat'ten ayrıldıktan sonra Saâdet gazetesine geçen Muallim Nâcî gazetenin edebiyat kısmını idare edeceğini duyurarak eski gazetesinde sürdüreceği tarzı Saâdet’te de sürdüreceğini ilan eder ve okuyucularını buraya çă̆ırır (Kolcu, 2018: 40-41).

Muallim Nâcî, Saâdet gazetesinde peş peşe yaptığı duyurulardan sonra 16 Ocak 1887'de aynı gazetenin sıradaki nüshasında Ukâz-ı Osmân̂̂ adında bir topluluk, şiir okulu kurduğunu açıklamıştır. Bu okula mensup şairler klasik şiirin nazım şekilleri -daha çok gazel- ve mazmunları, nazire-tazmin geleneği ile şiirler yazacaklardır. Başta gazelde ısrar edilse de daha sonraları mensur şiir, kıta, rubai formunda da şiirler yazılmaya başlanmıştır. Altı ay boyunca toplantılarına devam eden Ukâz-ı Osmânı̂ye İstanbul dışında Trabzon, İzmir ve Edirne'den de katılan isimler de olmuştur. Aralarında Ali Emirî Efendi, Hayret Efendi, Alî Rûhî, Üsküdarlı Talat, Üsküdarlı Sâfî, Maraşlı Kâmil, Harputlu Hayri, Hüseyin Hüsnü gibi isimlerin bulunduğu 35 ten fazla şairin şiiri ile katıldığı bu okul altıncı toplantıdan sonra faaliyetine devam etmemiştir.

Edebiyat mahfilleri hakkında detaylı bilgi için bkz.Anar, T. (2012). Mekândan Taşan Edebiyat. İstanbul: Kapı Yayınları. Adres | Address

RumeliDE Dil ve Edebiyat Araştırmaları Dergisi Osmanağa Mahallesi, Mürver Çiçeği Sokak, No:14/8 Kadıköy - İSTANBUL / TÜRKIYE 34714 e-posta: editor@rumelide.com

RumeliDE Journal of Language and Literature Studies

Osmanağa Mahallesi, Mürver Çiçeği Sokak, No:14/8

Kadıköy - ISTANBUL / TURKEY 34714

phone: +90 $5057958124,+902167730616$ 
652 / RumeliDE Journal of Language and Literature Studies 2022.26 (February)

One of the last poet school students of the Ottoman Empire: Hüseyin Hüsni and His Mecmau-i Edebiyye / Ö. Batğ Akman (pp. 650-657)

\section{Hüseyin Hüsnî Efendi ve Mecmûa-i Edebiyye'si}

Hüseyin Hüsnî Efendi Ukâz-ı Osmânînnin altıncı toplantısına katılmış isimlerden biridir. Hüsnî̀nin hayatı ve edebi kişiliği ile alakalı eldeki bilgiler oldukça sınırlıdır. Şair hakkında paralel bilgileri barındıran Tuhfe-i Nailî, Son Asır Türk Şairleri ve Osmanh Müellifleri’nden şairin İstanbul'da doğduğunu, Melamî meşrep bir şair olduğunu, bir zaman Mısır'a gidip 1890 yllında orada vefat ettiğini ve Kahire Mevlevîhânesi kabristanına defnedildiğini öğreniyoruz. Ayrıca şairin bilinen tek eserinin ilk sayfasında eser adından hemen sonra "Bâb-ı vâlâ-yı ser-askerî levâzımât-ı umûmiyye dâiresi ikinci şu'besi ketebesinden müteveffi Hüseyin Hüsnı̂” notu yer almaktadır. Buradan şairin Serasker Kapısı'nın Askeri Malzeme dairesinin ikinci şubesinde katiplik görevi yaptığını öğrenmekteyiz.

İbnülemin Mahmud Kemal İnal şairin şiirlerinin emsaline nispetle güzel olduğunu ve 1892'de Mecmûai Edebiyye adıyla basıldığını belirtmiştir (İnal, 1969: 684). Şiirlerinin şairin vefatından sonra basılması okunduğunun, şiirlerine rağbet edildiğinin bir göstergesi olabilir.

Şairin bilinen, eldeki tek eseri Mecmûa-i Edebiyye'dir. On altı sayfalık matbu bir eser olan Mecmua 1310/1892 yllında Mahmud Bey Matbaası3’nda basılmıştır.

Mecmûa-i Edebiyye Hüseyin Hüsnî’nin sanat anlayışı üzerine yorum yapabilmek için eldeki tek kaynak olduğundan kıymetlidir. Ukâz-ı Osmânî'de bir şiiri ile yer alan Hüsnî geleneğe bağlı, klasik şiir tarzında yazmayı benimsemiş olduğunu nispeten belli etse de onun detaylı değerlendirmeyi hakkeden bir şair olduğu kanaatindeyiz.

Mecmûa-i Edebiyye'de on bir gazel, bir tahmis, bir müseddes, Muallim Nâcînnin bir gazeline nazîre, Yenişehir Fenâr Müftisi Şair Meşhûr Merhûm İzzet Efendî’nin bir beytini tazmîn, bir kıta, üç tanesi Ukâz-ı Osmânî için yazılmış toplam beş rubai, ve iki manzume yer almaktadır. O dönemde şiir yazan neredeyse tüm isimler gibi Hüsnî de farklı nazım şekilleri denemekten çekinmemiştir.

Lirik bir şair olarak tanımlanabilecek olan Hüsnî’nin klasik şiirin hayal dünyasına oldukça hâkim olduğu anlaşılmaktadır. Hüsnî, sevgilinin güzellik unsurlarını bilir ve geleneğe uygun benzetmelerle onu tasvir eder.

Sevgili, melek yüzlüdür, seçkindir ve müstesna bir güzelliğe sahiptir. Servileri bile hayrette bırakacak işveli yürüyüşü ile yeni gelin gibi salınan sevgili, boyu en uzun olandır. Sevgili bir melektir onun özü, esası en saf nurdandır; fakat Allah onu insan suretinde yaratmıştır. Güzel olan sevgili ahlar kitabının anlatıcısıdır. Kâinat sevgilinin doğuşu ile aydınlanmıştır. Güneş gibi güzel olan sevgili ufukları nurlara gark etmiştir:

Fâilâtün Fâilâtün Fâilâtün Fâilün

Gerçi kim âlemde çok gördüm melek-sîmâ güzel

Görmedim bir sen gibi mümtâz ü müstesnâ güzel

Serviler hayretde kalsin şîve-i reftârına

Nev-arûs-âsâ salın ey kâmet-i bâlâ güzel

3 Eserin basım izni ile alakalı ön kapakta yer alan not şu şekildedir: "Maârif-i Nezâret Celîlesinin 151 numaralı fi 29 Şevval sene 1310 ve fi 3 Mayıs sene 1309 tarihli ruhsatnamesiyle tab' olunmuștur."

Adres $\mid$ Address

RumeliDE Dil ve Edebiyat Araşttrmaları Dergisi Osmanağa Mahallesi, Mürver Çiçeği Sokak, No:14/8 Kadıköy - İSTANBUL / TÜRKIYE 34714 e-posta: editor@rumelide.com

RumeliDE Journal of Language and Literature Studies

Osmanağa Mahallesi, Mürver Çiçeği Sokak, No:14/8

Kadıköy - ISTANBUL / TURKEY 34714

phone: +90 505 7958124, +90 2167730616 
Bir meleksin cevherin 4 nûr-ı mücerreddür fakat

Suret-i insanda hulk etmiş seni Mevlâ güzel

Bin hakikat keşfeder her bir nazarda çeşm-i cân

Bir kitâb-ı âh-ı nâtıksin sen ey ra'nâ güzel

Tal'atinden müstenîr olmakdadır hep kâinat

Gark-ı envâr etdin âfâkı mihr-âsâ güzel (Hüseyin Hüsnî, 1892: 4-5)

Hüsnî birkaç şiirinde klasik dönem şairlerinin pek çoğundan farklı bir tavır çizer. Şairde, sevgilinin her türlü cefasına boyun eğen, mihneti nimet kabul eden bir âşık değil bilakis değişen, başkaldıran âşık tipini görürüz.

Dönen devran Hüsnîyi mihnetiyle mahvedemez, o elemin etkisiyle ezilecek biri değildir. Mecnûn gibi avare ve divane değildir, o Leylâ dahi olsa Arap kızına gönül vermeyecektir:

\author{
Mefûlü Mefâîü Mefâîlü Feûlün \\ Mihnetle beni mahv edemez gerdiş-i gerdûn \\ Te'sîr-i elemle ezilir dâne miyim ben
}

Bint-i 'Araba dil veremem olsa da Leylâ

Mecnûn gibi âvâre vü dîvâne miyim ben (Hüseyin Hüsnî, 1892: 4)

Sevgiliye karşı açık sözlü olmaktan çekinmeyen Hüsnî dik başlı tavrını devam ettirerek ona irfan sahibi olduğunu, nazik tahrikine gerek olmadığını çünkü nefretini bildiğini söyler:

\title{
Feilâtün Feilâtün Feilâtün Feilün
}

Bizi tahkire nezâketle çahşma ey şûh

Anlaruz nefretüni sâhib-i irfânuz biz (Hüseyin Hüsnî, 1892: 4)

Muallim Nâcînin XIX. yüzyılda geleneğe bağlı şiir yazma yönündeki mevcut etki ve girişimleri dönemin şairleri üzerinde oldukça etkili olmuş bu sayede onlarca gazel ve nazire şiir yazılmıştır. Kolcu'nun tespitine göre Nâcînin en çok nazire yazılan gazelleri "eyledim meyhânede", "gözlerin" ve "gark-ı nûr" redifli gazelleridir (Kolcu, 2018: 29). Nâcînin bu tesirinin Hüsnî için de önemli olduğunu onun hem Ukâz-ı Osmânîye katılmasından hem de eserinde ona nazire bir gazel yazışından anlıyoruz. Hüsnî̀nin Muallim Nâcîye verdiği kıymet nazire şiirine verdiği başlıktan da -Muallim Nâcî Efendi Hazretlerinin Bir Gazel-i Âlâlerine Nazîredir- açıkça anlaşılmaktadır.

Hüsnî naziresini Nâcî’nin “gözlerin” redifli gazeline yazmıştır. Gazelde sevgilinin gözleri, güneşin ve ayın ışığını sönük bırakır; ateş gibi yakıcıdır; hem güler hem de zavallı âşığın canına kastedip onu öldüren oklar atar; bitmek bilmez zulüm icat eder; zalimdir, Allah korkusu bilmeden kirpiklerinin oklariyla âşığın kanını döker; saçları gibi siyahlığı ile Hüsnî’nin bahtını da bela karanlığına çevirmiştir:

\footnotetext{
$4 \quad$ Metinde kelime “cevherlerin” şeklinde yazılıdır fakat vezin gereği bu şekilde okunmuştur. Adres $\mid$ Address

RumeliDE Dil ve Edebiyat Araştırmaları Dergisi Osmanağa Mahallesi, Mürver Çiçeği Sokak, No:14/8 Kadıköy - İSTANBUL / TÜRKIYE 34714 e-posta: editor@rumelide.com RumeliDE Journal of Language and Literature Studies Osmanağa Mahallesi, Mürver Çiçeği Sokak, No:14/8 Kadıköy - ISTANBUL / TURKEY 34714 e-mail: editor@rumelide.com, tel: +90 5057958124, +902167730616 phone: +90 5057958124, +90 2167730616
} 
654 / RumeliDE Journal of Language and Literature Studies 2022.26 (February)

One of the last poet school students of the Ottoman Empire: Hüseyin Hüsni and His Mecmau-i Edebiyye / Ö. Batğ Akman (pp. 650-657)

\section{Fâilâtün Fâilâtün Fâilâtün Fâilün}

Nazra-sâz oldukça fârûkâne gâhî gözlerin

Münhasif eyler gider hûrşîd ü mâhı gözlerin

Bir nigâh-ı âteşîninden alur âteş kılıp

Nerden almıştır bu sûz-efgen nigâhı gözlerin

Hem güler hem tîr atar üftâdegânm bağrma

Âşık öldürmekle mi olmuş mübâhı gözlerin

Gamzeler olmakdadır gâret-ger-i mülk-i vücûd

Eyleyip îcâd-ı zülm-i bî-tenâhî gözlerin

Tîr-i müjgân âh mazlûmâne dökdü kanımı

Hiç zâlim bilmiyor havf-ı İlâhî gözlerin

Kâtil-i cân olduğun isbâta hâcet var mıdır

Gösterir hûniliğin zîrâ kemâhî gözlerin

Bahtını zülfün gibi bak Hüsnî-i bî-çârenin

Zulmet-âbâd-ı belâ kılmış siyâhı gözlerin (Hüseyin Hüsnî, 1892: 11-12)

Hüsnî Mecmûa-i Edebiyye'de, XIX. yüzyılın ilk çeyreğinde Yenişehir Fenâr Müftisi olarak görev yapmış şâir Ali İzzet Efendî’nin bir beytini tazmin ederek bu yolla bir muhammes yazmıştır. Bu beyit biyografi kaynaklarında da İzzet Efendi'ye kayıtlı muhtemelen eldeki sınırlı ve en bilindik şiirlerinden biridir. Fatin, tezkiresinde söz konusu beyti "matla-ı garrâsı beyne’z-zürefâ meşhur u zîbâterdür” şeklinde tanımlayarak bizlere bu matlanın zarif kimseler arasında meşhur olduğu bilgisini vermiştir (Çiftçi, ekitap: 346). Hüsnî’nin bu meşhur beyti tazmin yoluyla yazdığı muhammesinin son bendi aşağıdaki gibidir:

\section{Mefûlü Mefâ̂ilü Mefâillü Feûlün}

Fikr eyleyeli zülf-i siyeh-fâmını ey mâh

Fark eylemez olduk geceden gündüzü eyvah

Ahkâm-ı kadir böyle imiş neyleyelim âh

Aldık fitili mûm gibi şimdi yanarı

Üftâde-i hûbân-ı Yenişehr-i Fenârız (Hüseyin Hüsnî, 1892: 12-13)

Hakkında sınırlı bilgilere sahip olduğumuz Hüsnî’nin melâmî-meşrep genç bir şair olduğu biyografi kaynaklarında geçer. Aşağıdaki gazel bu tarzın dönemine göre iyi bir örneği sayılabilir. Gazel, Hz. Mûsâ'nın Tûr dağında vahiy ve tecelliye erişmesi olayına telmih ile başlamıştır. Sevgilinin yüzünü izleyen âşı öyle bir hayranlık içerisindedir ki, bundan sebep cennet hurilerinin sevdasından ayrı kalmıştır. Hallâc-ı Mansûr birlik arzusuyla "ene'l-Hak” haykırışında bulunduğu vakit saf bir nur yüzünde ateşlenir. Zahide gönderme yapmadan duramayan Hüsnî, onun vehimlerine, gerçekte olmayan

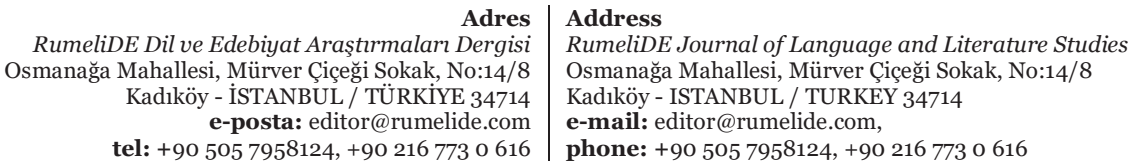


zanlarına varlık isnat ettiğini ve böylelikle uzaktan gördüğü serabı dahi sonsuz bir deniz sandığını ifade etmiştir. Son beyitte şair dünyanın baştanbaşa bir hakikatler evi olduğunu ve Hakk'a iman edenlerin, Hakk’a inanların bir karıncadan bin hakikat keşfedebileceğini vurgulamıştır:

\section{Fâilâtün Fâilâtün Fâilâtün Fâilün}

Mevceler peydâ olur sahrâ-yı dilde nûrdan

Bir tecelli-zârdır tefrik olunmaz Tûr'dan

Vech-i pâkinin temâşâsinda hayrândır gönüul

Ol sebebden fâriğim sevdâ-yı huld u hûrdan

Urduğu dem şevk-i vahdetle "ene'l-Hak" na'rasm

Nûr-ı mutlak müştaildi sûret-i Mansûr'dan

Zann-ı mevhûma vücûd isnâd edip zâhid yine

Zann eder bir bahr-ı bî-pâyân serâbı dûrdan

Bir hakâyık-hânedir âlem ki Hüsnî ser-be-ser

Bin hakîkât keșf eder Hak-bîn olan bir mûrdan (Hüseyin Hüsnî, 1892: 6)

Fuzûlî ve özellikle Şeyh Gâlib’in XIX. yüzyıl şairleri üzerinde ciddi etkileri vardır. Öyle ki Muallim Nâcî Ukâz-ı Osmânînnin Hüseyin Hüsnî̀nin de katılacağı altıncı toplantısının duyurusunda, toplantıya katılmak isteyenlere "Fuzûlî ve Şeyh Gâlib’ten örnekler vererek âşıkane, mutasavvifâne ve hâkimâne olmak üzere üçer rubâî yazmalarını ister" (Kolcu, 2018: 103). Bunun üzerine Hüsnî toplantıya Türk edebiyatında rubâî yazımında en çok tercih edilen ahreb grubundaki "Mefûlü Mefâîlün Mefầilün Fâ" vezni ile yazdığı aşağıdaki 3 rubâîsini gönderir.

Hüsnînnin toplantıya gönderdiği rubailerinden biri âşıkâne tarzdadır. Afet gibi güzel sevgilinin aşkına düşen âşığın ateşi günden güne şiddetle artar. Gam askeri gönül yurdunu talan ettiği için âşık, feryat ve figan etmededir:

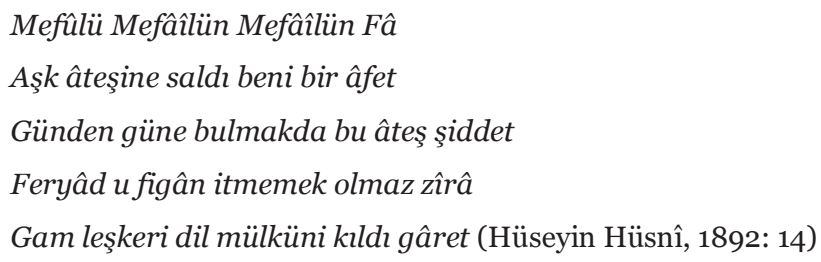

Tasavvuf felsefesine göre kişinin varlıkta birliği gördüğü vahdet ve bunun tam karşıtı çokluk anlamına gelen kesret, klasik Türk şiirinde şairlerin çok sık kullandığı iki terimdir. Hüsnînnin de katılacağ toplantının "mutasavvıfâne" çağrısına uyarak yazdı̆̆ı aşağıdaki rubai bu iki terim etrafında dönmektedir. Birliğin ancak çoklukta, çokluğun ise birlikte aşikâr olduğu döngüsünü yalın bir şekilde ifade etmiştir:

\section{Mefûlü Mefâilün Mefâîlün Fâ}

Kesrette bulur ârif olanlar vahdet

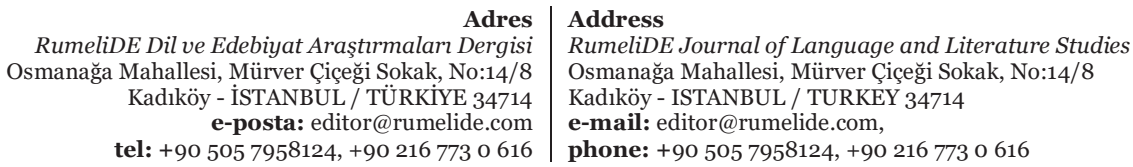


656 / RumeliDE Journal of Language and Literature Studies 2022.26 (February)

One of the last poet school students of the Ottoman Empire: Hüseyin Hüsni and His Mecmau-i Edebiyye / Ö. Batğ Akman (pp. 650-657)

Vâkıflara vahdetde ayândır kesret

Zann itme cüdâ kendini hakdan zinhâr

Tâ seleb ola bu aradaki gayret (Hüseyin Hüsnî, 1892: 14)

“Okuyup yazmaz bir çocuğa pederinin hitâbı" notu ile eserde yer alan ve Ukâz-ı Osmânı̂ye gönderilen son rubai ise Hüsnî’nin hâkimâne tarzda yazdığı rubaidir. Nâbı̂’nin oğlu Ebu'l-Hayr Mehmed Çelebi için yazdığı öğüt kitabı olan Hayriyye'deki samimi duyuşa yakın bir ifadeye sahip rubai tahsile gereken önemi vermeyen bir çocuğa babasının dilinden bir öğüttür.

Cehalet vadisinde dolaşma böyle, ilim tahsil edeceksen söyle. Yersiz susuşların artık yeter. Akıllı olan kulluk eder mi böyle:

Mefûlü Mefâîlün Mefâîlün Fâ

Vadî-i cehâletde dolaşma böyle

Tahsil-i kemâlât edeceksen söyle

Söyle yeter artık bu sükût-ı bîcâ

Âkil olan eyler mi taabbüd öyle (Hüseyin Hüsnî, 1892: 14)

Hüsnînnin yazdığı tek kıta aşağıdakidir. Sel gibi akan gözyaşlarının taş kalpli sevgiliye kâr etmemesi, yeryüzünde gece gündüz tufan kopsa sert taşlara yağmurun hiç mi hiç tesir etmeyecek olmasına benzetiliyor. Hüsnî bu kıta için düştüğü notta son mısraının İran şairi Hâfız-ı Şirâzî’nin “der seng-i hâre katre-i bârân eser ne-kerd” mısraından alınma gibi olduğunu ifade etmiştir:

\author{
Mefûlü Fâilâtü Mefâîlü Fâilün \\ Kâr eylemezse seyl-i sirişkim aceb midir \\ Âhen misâli kalbi olan meh-pâreye \\ Tûfân koparsa rûy-ı zemîn üzre rûz u şeb \\ Bârân ider mi hiç eser [ol] seng-i hâreye (Hüseyin Hüsnî, 1892: 16)
}

\title{
Sonuç
}

Klasik devirde nazire yazmak, mecmua tertip etmek, şair meclislerinde bir araya gelmek birer mektep görevi görüp şiir meşkine olanak sağlayan talimler ve muhitler olarak dikkat çekmekteydi. Bu geleneğin belki de son şair okulu Muallim Nâcî’nin muallimlik yaptığı dönemde son öğrencilerini yetiştirmiştir. Muallim Nâci ve ekibinin kurduğu Osmanlı’nın son şair okulu varlığını uzun süre devam ettiremese de dönemin hevesli ve anlayışa hâkim şairlerini bir araya getirmiş olması bakımından önemlidir. Hüseyin Hüsnî de bu öğrencilerden biridir.

Hüsnînnin hayatı hakkında bildiklerimiz sınırlıdır fakat günümüze ulaşan eseri onun edebi yönü hakkında bizlere kıymetli bilgiler sunmuştur. Farklı nazım şekillerinde şiir yazmaktan çekinmeyen şair, mecmuasını adeta bir meşk defteri olarak kullanmıştır. Gayr-ı mürettep bir formda olan mecmuadaki şiirler, gazel, tahmis, müseddes, nazire, tazmin, kıta ve rûbâî şeklinde sıralanmıştır. Hacimli olmayan, küçük mecmuasından seçtiğimiz örnekler Hüsnînnin aruz veznine hâkimiyetini, benzetmelerdeki başarısını, Arapça-Farsça kelime ve tamlama kullanımındaki hakimiyetini okuyucuya sunmaktadır. Hüsnî’nin şiirlerinde aruz kusurları oldukça azdır. Şairin redif ve kafiye tercihleri incelendiğinde, redif yapmada kelime kullanımı kadar, ek kullanımından da istifade ettiğini görmekteyiz. Bütün bu kullanımlar klasik dönem şairlerinin tercihleri ile paralellik arz etmektedir.

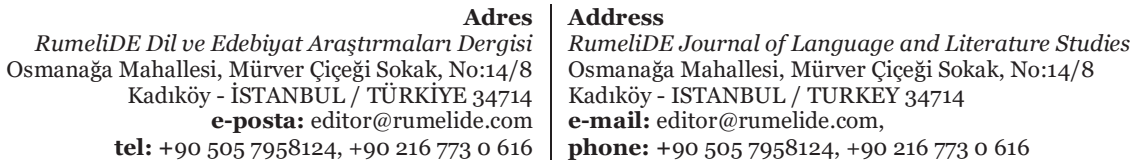


Sevgilinin neredeyse tüm özelliklerine vâkıf olan Hüsnî’de sıradan âşık tipinin yanında değișen, sevgiliye başkaldıran âşık tipini de görürüz. Hüsnî’nin Ukâz-ı Osmânî için yazması istenen ısmarlama şiirlerde "âşıkâne, mutasavvifâne ve hâkimâne" başlıklı konuları kendi dönemine göre başarılı bir şekilde işleyerek iyi bir Klasik şiir okuyucusu olduğunu âdeta ispat etmiştir.

Hüsnî, Fuzûlî, Şeyh Gâlip, Nâbî ve İran şairi Hâfız gibi isimlerin duyuşlarını şiirine aksettirmeyi başarmış bir son dönem şairidir. Onun Nâcî̀ye yazdığı nazire şiir ve İzzet Efendî’nin bir beytini tazmini diğer şairlerle edebi bir ilişki içinde olduğunun ve vadide görünür olma çabası güttüğünün göstergesi sayılabilir.

Hüseyin Hüsnî, sosyal ve kültürel bakımdan gelenekten uzaklaşılan "yeni” sanat üretme "yeni” yaşayış tertip etme kaygısının hâkim olduğu bir dönemde klasik şiirin altın çağını yaşadığı zamanların duyuşu ile şiir yazmış ve bunu bir okul mensubiyeti ile taçlandırmış önemli bir isimdir. Onun bilinen tek eseri olan Mecmûa-i Edebiyye içerdiği şiirler bakımından klasik şiirin mazmun ve imajlarını, şekil özelliklerini başarılı bir şekilde yansıtmaktadır.

Hüseyin Hüsnî Efendi hakkında bundan önce bildiklerimiz sadece biyografik birkaç bilgi ve eser adı ile sınırlı idi. Bu çalışma ile onun Ukâz-ı Osmânî mensubiyeti, Mecmûa-i Edebiyye'si ve şiir sanatı ilk kez ilim alemine tanıtılmıştır.

\section{Kaynakça}

Anar, T. (2012). Mekândan Taşan Edebiyat. İstanbul: Kapı.

Çağın, S. (2020). “Muallim Naci”. Türk Edebiyatı İsimler Sözlüğü (TEİS). http://teis.yesevi.edu.tr/madde-detay/muallim-naci (Erişim Tarihi: 11.11.2021).

Çiftçi, Ö. (2017). Fatîn Tezkiresi (Hâtimetü’l-Es,âr). https://ekitap.ktb.gov.tr/Eklenti/55976,fatintezkiresi-pdf.pdf?o (Erişim Tarihi: 26.11.2021).

Hüseyin Hüsnî Efendi (1892). Mecmûa-i Edebiyye. İstanbul: Mahmûd Bey Matbaası.

Kolcu, A. İ. (2018). Osmanlının Son Şair Okulu Ukâz-ı Osmânî. Erzurum: Salkımsöğüt.

Kurnaz, C. (2007). Osmanl Şair Okulu. Ankara: Birleşik.

Kurnaz, C., \& Tatçı, M. (2000). Bursalı Mehmed Tahir, Osmanlı Müellifleri, C.I. Ankara: Bizim Büro.

Kurnaz, C., \& Tatçı, M. (2001). Mehmed Nâil Tuman, Tuhfe-i Nâilî-Divan Şairlerinin Muhtasar Biyografileri, C.II. Ankara: Bizim Büro.

İnal, İ. E. M. K. (1969). Son Asrr Türk Şairleri, Cüz 1. İstanbul: Milli Eğitim.

Özgül, M. K. (2012). XIX. Asrnn Özel Bir Mahfeli Olarak Encümen-i Şu’arâ. Ankara: Kurgan Edebiyat. Uçman, A. (2005). "Muallim Nâcî". TDV İslam Ansiklopedisi, C.3o. İstanbul: Türkiye Diyanet Vakfi.

\footnotetext{
Adres
RumeliDE Dil ve Edebiyat Araștırmaları Dergisi Osmanağa Mahallesi, Mürver Çiçeği Sokak, No:14/8 Kadıköy - İSTANBUL / TÜRKIYE 34714
e-posta: editor@rumelide.com

RumeliDE Journal of Language and Literature Studies Osmanağa Mahallesi, Mürver Çiçeği Sokak, No:14/8 Kadıköy - ISTANBUL / TURKEY 34714 tel: +90 5057958124, +90 2167730616 